\title{
Viscosity Differences Between Various Guar Gums
}

\author{
N. O'Connor, J. Tredger and L. Morgan \\ Department of Biochemistry, University of Surrey, England
}

\begin{abstract}
Summary. Guar gum from four industrial sources was investigated. The viscosity of two preparations of hydrated guar gum in the form of powdered flour and one granulate flour was measured at $22^{\circ}$ and $32^{\circ} \mathrm{C}$ and $\mathrm{pH} 1.0$ and $\mathrm{pH} 4.0$. Viscosity measurements on wax-coated guar granules proved impossible but visual assessment indicated an extremely low viscosity in all conditions. These findings were compared with the ability of the equivalent of $5 \mathrm{~g}$ guar gum of the various preparations to modify the absorption of a $50 \mathrm{~g}$ liquid glucose load. The mean post-prandial blood glucose curve was not significantly different from the control situation after the incorporation of each preparation. Despite the granulate flour attaining a considerably lower viscosity than the powdered flour they were equally effective in significantly reducing the mean post-prandial insulin curve (area under the curve ( $0-180 \mathrm{~min})$ reduced by 46 and $50 \%$ respectively). The wax-coated granules which achieved minimal viscosity caused significantly less reduction of post-prandial insulin levels (area under the curve reduced by $37 \%$ ). The viscosity of guar gum upon hydration is of importance in assessing the efficacy of a preparation in clinical use.
\end{abstract}

Key words: Guar gum, viscosity, glucose tolerance

Guar gum has been employed in the dietary treatment of diabetes and shown to improve glucose tolerance $[1,2]$. This property has been attributed to the viscosity of the hydrated guar gum which reduces the rate of gastric emptying [3] and possibly the rate of diffusion of nutrients in the gut. Jenkins et al. have shown that when guar gum is hydrolysed with a subsequent reduction in viscosity, its efficacy is greatly diminished [4]. There has, however, been considerable controversy in the literature over the degree of effectiveness of guar gum in various situations
[5-11]. During several years of clinical trials we have used preparations of guar gum supplied by three industrial sources and noted marked differences in the ability of these preparations to hydrate. We have, therefore, measured the viscosity of solutions of these preparations under varying conditions and compared their viscosity to their physiological action.

\section{Method}

\section{Sources of Guar Gum}

Four preparations of guar gum were provided by three industrial companies: a) two powdered guar flour preparations (Boots and Norgine); b) one granulate guar flour preparation (Speywood); c) one preparation of guar coated in liquid paraffin and paraffin wax to form large granules (Norgine).

\section{Measurement of Viscosity}

Solutions of each preparation $(1 \mathrm{~g} / 100 \mathrm{mI})$ were made up with either tap water ( $\mathrm{pH} 4.0$ ) or tap water acidified to $\mathrm{pH} 1.0$ with concentrated hydrochloric acid and maintained at $22^{\circ}$ and $32^{\circ} \mathrm{C}$. Each solution was prepared by whisking the guar gum vigorously into the water. The point at which the addition began was taken as the start of the hydration time.

Viscosity measurements were made with a Brookfield Synchro-Lectic Viscometer (model RVF-100, spindle no. 4 at $20 \mathrm{rev} . / \mathrm{min}), 2,5,10,20,30$ and 45 or $60 \mathrm{~min}$ from the start of hydration. Experiments were carried out in duplicate. Further measurements were made after $28 \mathrm{~h}$ hydration on solutions at $\mathrm{pH}$ 4.0 maintained at $22^{\circ} \mathrm{C}$.

\section{Clinical Studies}

Five healthy volunteers (two males and three females) who were within $10 \%$ of their ideal body weight and aged between $22-25$ years took part in the study.

Each subject attended on four separate occasions at least a week apart. After an overnight fast they each consumed in two equal portions a minute apart $80 \mathrm{mI}$ Hycal (Beechams) diluted to $250 \mathrm{ml}$ with water. This provided $50 \mathrm{~g}$ glucose. On two occasions each portion contained in addition $5 \mathrm{~g}$ powdered flour (Norgine) or granulate flour (Speywood) which was whisked into it immediately prior to consumption. During the other session they chewed 


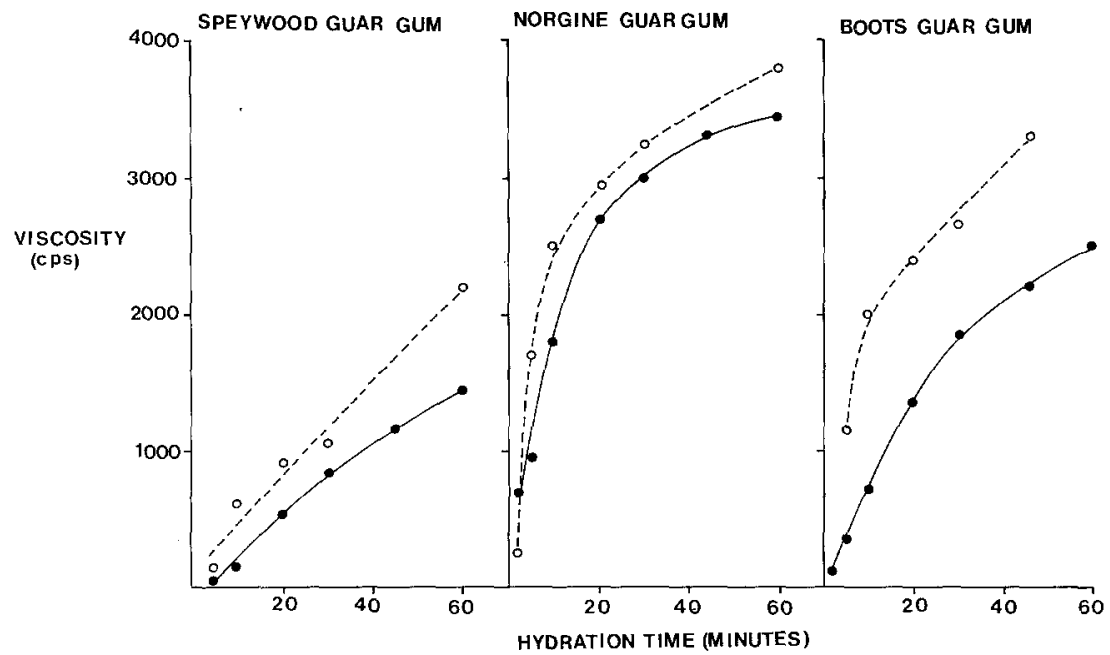

SPEYWOOD GUARGUM NORGINE GUAR GUM

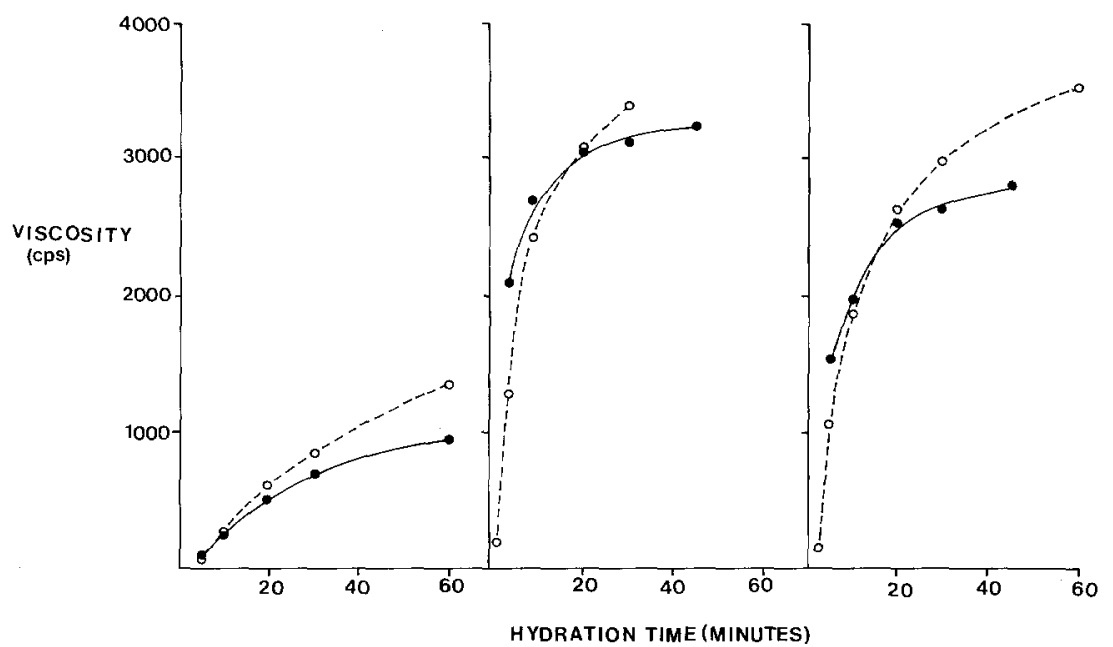

Fig. 1. Effect of temperature on the viscosity development during hydration of three guar gum preparations at $\mathrm{pH} 4.0$ $\longrightarrow 32^{\circ} \mathrm{C} ; \mathrm{O}-\mathrm{O}-\mathrm{O} 22^{\circ} \mathrm{C}$
Fig. 2. Effect of temperature on the viscosity development of three guar gum preparations at $\mathrm{pH} 1.0$
$6.25 \mathrm{~g}$ wax-coated granules (equivalent to $5 \mathrm{~g}$ guar gum) before taking the drink.

Venous blood samples were collected from an indwelling venous cannula (kept patent with $3.8 \%$ sodium citrate) in the fasted state and at $20,40,60,80,100,120,150$ and $180 \mathrm{~min}$ from the start of consumption while the subjects were at rest. The samples were analysed for glucose by a glucose oxidase method [12] and insulin using a double antibody radioimmunoassay technique [13]. Results were compared using Student's t-test for paired data.

The study was approved by the Ethics Committee of St. Luke's Hospital and each subject gave their informed consent.

\section{Results}

\section{Viscosity Measurements}

It was impossible to obtain reproducible viscosity measurements on the wax-coated Norgine granules, as the granules swelled sightly but did not form a uniform solution. However, visually assessed, the wax-coated granules formed very much less viscous solutions than any of the other preparations.

The effects of $\mathrm{pH}$ and temperature on the viscosity of the other guar gums are shown in Figures 1 and 2 . The viscosities the various guar solutions attained were dependent on time, temperature and $\mathrm{pH}$. All the preparations were less viscous at the higher temperature. The situation was a complex one, and the extent to which these factors influenced viscosity varied in each individual preparation. On every occasion the Speywood granulate flour was much less viscous during the first hour of hydration then the Boots or Norgine powdered flours. At $\mathrm{pH} 4.0$ and $22^{\circ} \mathrm{C}$ their relative differences were still apparent after $28 \mathrm{~h}$ (3,100 centipoises (cps), 4,600 cps and 4,700 cps respectively). At both $22^{\circ}$ and $32^{\circ} \mathrm{C}$ the Speywood product was less viscous at $\mathrm{pH} 1.0$ than at $\mathrm{pH} 4.0$. This is in contrast to the other two flours which were generally more viscous at $\mathrm{pH} 1.0$ at both tempera- 

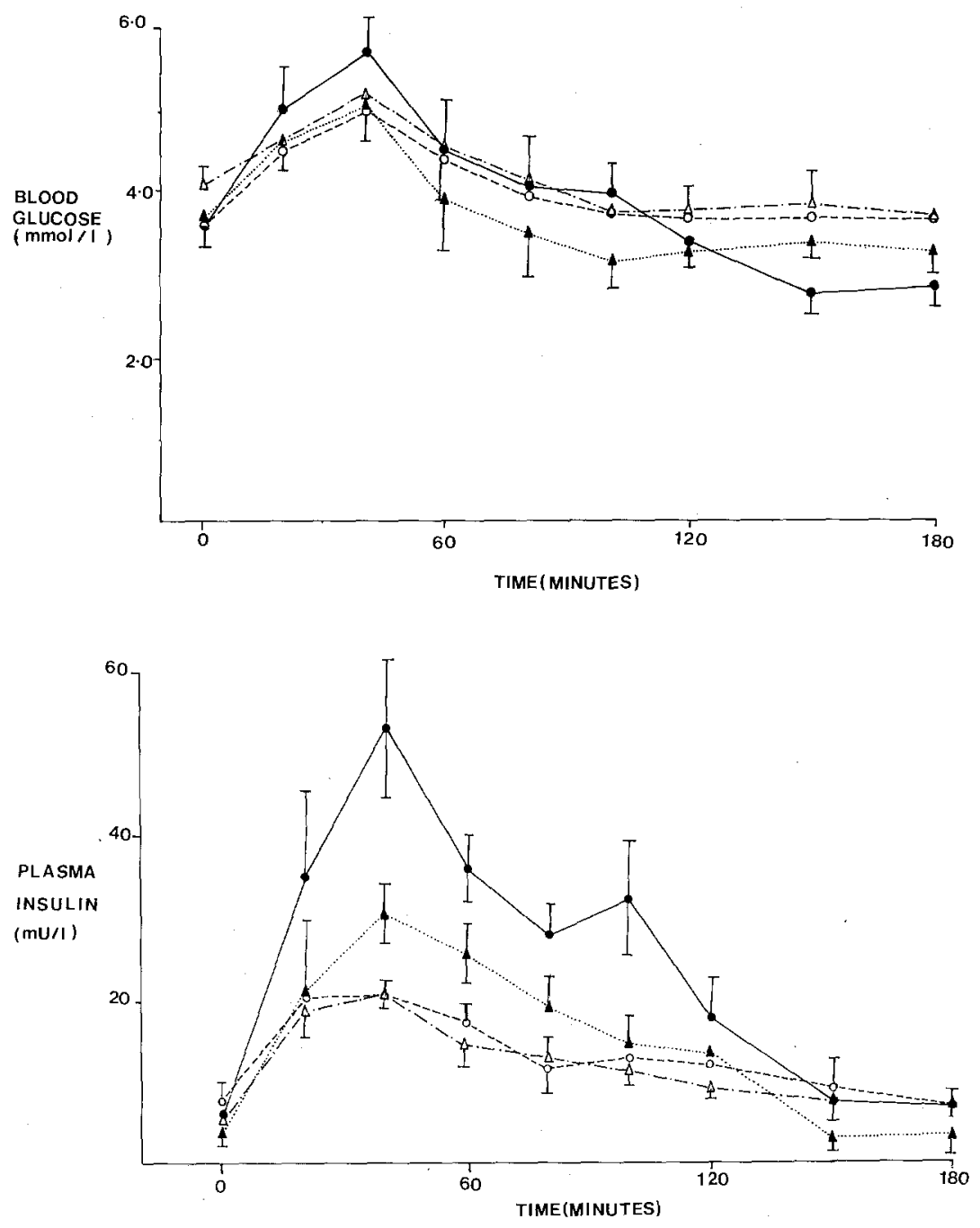

Fig. 3. Effect of three guar gum preparations on mean $( \pm S E M)$ post-prandial glucose levels following a $50 \mathrm{~g}$ liquid glucose load $(\mathrm{n}=5)$. $-50 \mathrm{~g}$ glucose (control); $\mathbf{\Delta}-\mathbf{\Delta}-\mathbf{\Delta} 50$ g glucose + Norgine wax-coated granules; O-O-O $050 \mathrm{~g}$ glucose + Speywood granulate flour; $\triangle-\triangle-\triangle 50 \mathrm{gglu}-$ cose + Norgine powdered flour
Fig. 4. Effect of three guar gum preparations on mean ( \pm SEM) post-prandial insulin levels following a $50 \mathrm{~g}$ liquid glucose load $(n=5)$. (For symbols see Fig. 3) tures. The reproducibility of duplicate experiments was $88.5 \pm 1.6 \%$ (mean $\pm \mathrm{SEM}$ ).

\section{Clinical Studies}

Addition of guar to the glucose drink had no statistically significant effect upon mean peak blood glucose levels, although peak post-prandial blood glucose levels when each of the three guar preparations were taken with the glucose load were lower than the control (Fig. 3). In the second part of the experiment (90-180 $\mathrm{min}$ ) addition of guar had in each case the effect of preventing a fall in blood glucose to below fasting levels, thus 'smoothing' the post-prandial glucose curve compared with the control. The waxcoated granules were least effective in this respect, but there were no statistically significant differences in blood glucose levels between any of the different guar preparations.

In contrast, post-prandial insulin levels (Fig. 4) were significantly reduced by addition of each of three preparations of guar to the glucose load. [Area under the curve $0-180$ min significantly smaller with wax coated granules (Norgine) $(p<0.025)$, Norgine powdered flour $(p<0.01)$ and Speywood granulate flour $(p<0.01)]$. The Norgine and Speywood flours were equally effective in reducing post-prandial insulin levels compared with the control, but the Norgine wax-coated granules were significantly less effective than the other two flours [area under the curve $0-180 \mathrm{~min}$ significantly greater with wax-coated granules than with either flour $(p<0.05)]$.

\section{Discussion}

Guar gum is a galactomannan derived from the leguminous plant, Cyamopsis tetragonoloba, grown in India, Pakistan and the United States. Climatic differences may affect the degree of cross-linking of the galactomannan chains. We suggest this may be partly responsible for the variations in viscosity seen 
between the Boots and Norgine guar gum flours. Both these products are in the form of a powdered flour, whereas the Speywood company specially process the flour to produce a granulate which is more readily miscible with water. This processing may provide an explanation for the marked differences in viscosity development between the Speywood granulate flour and the other two flours. The wax-coated guar gum granules (Norgine) hydrated poorly and this is the probable reason for their very much lower viscosity compared with the other guar preparations.

If the action of guar gum is to delay gastric emptying by virtue of its ability to hydrate in the stomach then one might expect the differences in rates of viscosity development and maximum viscosity attained to mimic its physiological effectiveness [3]. We compared the effect of incorporating into a liquid glucose load a) Norgine powdered guar flour, which was the most viscous at $\mathrm{pH} 1.0$ and $32^{\circ} \mathrm{C}$ (similar to conditions in the stomach), b) Speywood granulate guar flour, which not only had a lower viscosity but whose viscosity was adversely affected by acid conditions, and c) Norgine wax-coated guar granules, the least viscous preparation. All three guar products were effective in slowing down glucose absorption in a liquid test meal situation as shown by reduction in mean post-prandial insulin levels compared with the control. However, whilst the least viscous wax-coated granule preparation was the least effective, the two guar flours were equally effective in spite of widely different viscosities. It therefore appears that following a liquid test meal a low-threshold viscosity attainment is sufficient for the observed effects. However, guar has been shown to be less effective when incorporated into solid test meals [14] where conditions are not as favourable for the attainment of maximum viscosity. In this situation, differences in viscosity between guar preparations might become more important. We have shown that the wax-coated guar granules were ineffective when given as a pre-meal medication to a solid mixed meal in both healthy volunteers and maturity onset diabetics (Tredger, O'Connor and Morgan, unpublished observations). It is also possible that the mode of action of guar gum is not solely by virtue of its viscosity. Other possible modes of action could include:

1. creation of an effective barrier between nutrients and absorptive sites;

2. interference with the active transport mechanism by 'mopping up' $\mathrm{Na}^{+}$ions;

3. altered release of gastrointestinal hormones with a concurrent increase in insulin sensitivity.

This latter hypothesis has some foundation. Morgan et al. have found that GIP secretion is modified by guar [2] and reduced 24-h urinary 3-hydroxybu- tyrate outputs were found in diabetics on guar supplemented diets [15], indicating a probable reduction in fat metabolism.

We believe that guar gum would be a useful adjunct to the conventional treatment of diabetes and that it can be successfully incorporated into the dietary regimen. However, further studies are necessary to establish the characteristics of guar gum which are critical to its activity in physiological conditions. In the meantime, to prevent further confusion, the source and type of guar gum used should be specified in all reports of clinical trials.

\section{References}

1. Jenkins DJA, Goff DV, Leeds AR, Alberti KGMM, Wolever TMS, Gassull MA, Hockaday TDR (1976) Unabsorbable carbohydrates and diabetes: decreased post-prandial hypoglycaemia. Lancet 2: 172-174

2. Morgan LM, Goulder TJ, Tsiolakis D, Marks V, Alberti KGMM (1979) The effect of unabsorbable carbohydrates on gut hormones. Diabetologia 17: 85-89

3. Holt S, Heading RC, Carter DC, Prescott LF, Tothill P (1979) Effect of gel fibre on gastric emptying and absorption of glucose and paracetamol. Lancet 1: 636 639

4. Jenkin DJA, Leeds AR, Gassull MA (1977) Viscosity and the action of unavailable carbohydrate in reducing post-prandial glucose and insulin levels. Proc Nutr Soc 36: 44A

5. Wolever TMS, Taylor R, Goff DV (1978) Guar: viscosity and efficacy. Lancet 2: 1381

6. Williams DRR, James WPT (1979) Fibre and diabetes. Lancet 1: $271-272$

7. Jenkins DJA, Nineham R, Craddock C, Craig-McFeely $\mathbf{P}$, Donaldson K, Leigh T, Snook J (1979) Fibre and diabetes. Lancet 1: 434-435

8. Wolever TMS, Taylor R, Goff DV, Aherne J (1979) Fibre and diabetes. Lancet 1: 435

9. Goulder TJ (1979) Guar and diabetes. Lancet 1: 612

10. Williams DRR, James WPT (1979) Guar and diabetes. Lancet 1: 612

11. Dewar J, Garcia-Webb P, Shenfield GM (1979) Guar and diabetes. Lancet 1: 612-613

12. Morley G, Dawson A, Marks V (1968) Manual and autoanalyser methods for measuring blood glucose using guaicum and glucose oxidase. Ann Clin Biochem 5: 42-45

13. Samols E, Bilkus DA (1964) A comparison of insulin radioimmunoassays. Proc Soc Exp Biol Med 115: 79-84

14. Wolever TMS, Jenkins DJA, Nineham R, Alberti KGMM (1979) Guar gum and reduction of post-prandial glycaemia: effect of incorporation into solid food, liquid food and both. Br J Nutr 41: 505-510

15. Jenkins DJA, Wolever TMS, Nineham R, Goff DV, Haisman P, Charnock P, Taylor RH, Hockaday TDR (1979) Dietary fibre and ketone bodies: reduced urinary 3-hydroxybutyrate excretion in diabetics on guar. $\mathrm{Br}$ Med $\mathbf{J} 2: 1555$

Received: 12 June 1980

and in revised form: 5 December 1980

Jacki Tredger

Department of Biochemistry

University of Surrey

Guildford GU2 5XH

England 